\title{
The Economist's Way of Thinking About Alcohol Policy
}

\author{
Harry Clarke ${ }^{1}$
}

\begin{abstract}
This paper assesses policy interventions in alcoholic drink markets from an economic perspective. This perspective assumes that alcohol yields consumption benefits as well as costs, and that society's utilitarian objective is to maximise the excess of alcohol's benefits over its costs. The economic perspective rejects the common community focus on the 'gross cost of illness' consequential to alcohol consumption. The economic approach to alcohol policy instead emphasises information, self-control and the external costs of consuming alcohol. For consumers with alcohol dependencies, a policy mix emphasising the role of cues and self-control is suggested.
\end{abstract}

\section{Introduction}

Australian adults drank on average 9.8 litres of 'drinking alcohol' (ethanol) per capita in 2004-05. Some 13.4 per cent drank at 'risky' levels, this percentage having grown 50 per cent over the previous 10 years (ABS 2006). ${ }^{2}$ Some drinkers spent substantial resources controlling their drinking: 37 per cent of clients seeking treatment for drug dependency saw alcohol as the primary drug of concern (AIHW 2006). Finally, alcohol is (after tobacco) the second-largest cause of drug-related hospital admissions and the main cause of deaths on roads (ABS 2006).

This paper examines policy interventions in alcoholic-drink markets from an economic perspective. This approach rejects the paternalism which opposes drinking alcohol because of claimed high gross costs. Instead, it assumes that alcohol yields consumption benefits (in taste and effects) as well as costs, and that society's utilitarian objective is to maximise the excess of its benefits over its costs.

Consuming alcohol, then, is viewed for the most part, as a social, recreational activity - a social lubricant that enhances the enjoyment of life. For most, using alcohol is an informed, rational choice with relatively harmless implications a perspective not typically adopted by medical and public-health researchers.

\footnotetext{
1 The Department of Economics and Finance, La Trobe University, h.clarke@latrobe.edu.au.

2 For males, consumption of up to 28 standard drinks per week was 'Low risk', 29-42 per week 'Risky', and 43 or more 'High risk'. For females, consumption of up to 14 standard drinks was 'Low risk', 15-28 per week 'Risky', and 29 or more 'High risk'. A standard drink contains 10 grams of alcohol, so the average male drinks 980 standard drinks per year or 19 per week.
} 
The analysis recognises, however, that alcohol consumption has important costs, particularly when consumed at high levels or in risky settings. Consumption can have harmful physical and mental health effects and can lead to anti-social, dangerous behaviour such as drink-driving and violence, particularly within the family. These costs become important to an economic liberal when they are not borne by individual consumers or when there are issues of information failure or failure of self-control.

But from an economics perspective even substantial harm caused by alcohol consumption does not, by itself, suggest alcohol use should be restricted. The presumption is that usually individuals are the best judges of their own welfare. Thus, provided the potential for harm is recognised by users, and harms are borne by users who assess them rationally by comparing benefits to costs at the margin, restrictions are redundant. The presumption is that alcohol consumption provides net benefits to most adults who make informed individual choices.

This paper provides a framework that can assess the government policies have been devised to regulate the terms under which alcohol is consumed. Medical and non-economic approaches are examined and then reasons for intervention provided. Information, self-control and externality-based policies are discussed, before final remarks are made.

\section{Medical and non-economic approaches}

Much community focus on alcohol consumption looks at adverse health and neuropsychiatric consequences. This 'gross cost of illness' approach to estimating the consequences of consumption (Godfrey 2004) focuses on the health costs of excessive drinking, whether this occurs regularly or episodically, and with related dependence issues. There is concern with social problems associated with drinking, in the workplace and home, with crime, intentional cause of injury and with drinking on inappropriate occasions such as prior to driving. Particular attention is directed to youth drinking (RACP 2005; WHO 2004).

This emphasis helps identify health and other cost implications of alcohol consumption but does not help much in designing policy. To what extent should consumption be restricted? What are the costs, in terms of foregone benefits, of restricting consumption?

That drinking alcohol can be risky does not, in itself, imply much about its desirability or the extent to which it should be restricted. The question is how to value associated costs and benefits. Economics does this by assigning monetary values to individual choices and to any consequent costs or benefits that spill over as externalities. Policy then seeks interventions which maximise the difference between social benefits and costs.

Drinkers maximise this difference themselves by making informed choices, provided there are no external costs or benefits. They then both maximise 
individual and the social advantage. With external costs, however, free markets will not achieve this. A restriction to reduce consumption to the point where net social benefits are maximised then makes sense provided the cost of the restriction is less than the net benefits lost by not employing it, establishing a case for policy activism.

If consumers are aware of risks and costs of activities (whether drinking alcohol, smoking cigarettes, driving a car or bungy-jumping) there is no a priori case for policy restrictions without external costs. Focusing on minimising gross health costs alone suggests extreme, prohibitive policies.

The hypothesis that people make consumption choices rationally, using sound information, can be questioned given the scale of alcohol-abuse issues. Numerous people have self-control problems with respect to alcohol. Others fail to identify harmful consequences of consumption. This provides arguments for better information and for improving decision-making skills.

\section{Rationales for intervention}

There are three market imperfections that create a case for restricting alcohol consumption, and a fourth, realpolitik, reason: paternalism.

I. Information: Efficiency in market exchange requires that the purchaser of a product understands its characteristics. With respect to alcohol, an issue is whether consumers understand that alcohol is a neurotoxin that destroys brain cells, with few health benefits (Fillmore et al. 2006). It is also unclear whether consumers understand the genetic and neurobiological bases for alcohol self-control problems.

The information difficulties are compounded by private-sector advertising and alcohol promotion which links consumption to sporting and social prowess. There is evidence that such advertising has significant consumption effects, particularly among adolescents, where motivations for risk-taking, novelty-seeking and peer-driven behaviour increase the probability of alcohol experimentation (Saffer and Dave 2003). ${ }^{3}$

Finally, particular age, ethnic and socio-economic groups have poor information. The failure to provide information about the negative consequences of drinking alcohol is a market failure since information is a public good. Markets will develop to promote alcohol consumption since this benefits commercial interest, but there are diminished private incentives to provide information presenting possible negative outcomes.

On the other hand, there is evidence that some young people overestimate risks associated with alcohol consumption - particularly risks of becoming

3 The effects on adult behaviour are less clear (Nelson 2003). 
alcoholic. This overestimation leads to less drinking than would occur were risks accurately perceived (Lundborg and Lindgren 2002). The same type of finding has been observed with respect to smoking, where most overestimate risks of adverse health consequences (Viscusi 2002). To the extent that this is true, public-information campaigns that seek accurate perceptions of health costs should, paradoxically, be oriented towards calming fears of risks rather than heightening awareness of them.

2. Self-control issues: Alcohol consumption can be addictive and people may have problems controlling their consumption. Alcoholism is a chronic, relapsing disorder characterised by a preoccupation with obtaining alcohol and a loss of control over consumption. Self-control problems can be triggered by impulsiveness that is, in turn, generated by advertising and other cues. There are particular issues of self-control among youth, who have high impulsiveness, as well as among those with particular genetic predispositions (Goldstein 2001).

3. Externalities: Alcohol consumption creates private costs for individuals and social costs for those who interact with alcohol consumers and the broader community. Drink-driving is the most serious cause of traffic accidents (Phelps 1997), with 28.5 per cent of road deaths of those aged under 65 attributed to alcohol (ABS 2006). Violent behaviour by intoxicated persons is also a serious issue.

Other alcohol-linked externalities include foetal alcohol syndrome and harms caused by drinkers to family members. Some economists ignore intra-family costs on the basis that family units are regarded as making mutual consumption decisions. This is not so with most alcohol consumption, so family costs are best regarded as a third-party impact.

In addition, since Australia has a publicly funded national health scheme the medical costs of alcohol consumption are not only private. Above-average medical costs will be met partly from the public purse, providing a public-interest case for restrictions.

4. Paternalism: Although not a market-failure reason for intervention, there are moral and emotional arguments against excessive alcohol consumption. Some 'wowsers' oppose alcohol consumption even if well-informed consumers, without self-control problems, bear all consumption costs.

Paternalism should result in alcohol taxes being set above externality-correcting levels. It motivates public-health campaigns to decrease consumption not because external costs are generated but because reduced consumption is the social objective.

For policy purposes, paternalistic arguments are unhelpful because they do not take one far in developing a rationale for policy. Alcohol consumption is opposed because certain groups in the community - doctors, scientists, religious 
leaders - assess it to be undesirable. However, considering paternalism as a policy motivation is useful for understanding actual government policies which can be assessed, independently of externalities, purely in terms of how well they restrict consumption.

\section{Policy Interventions}

Market-failure reasons for policy intervention suggest various policy options.

I. Information-related policies: The public sector may need to intervene to provide information about negative consequences of consuming alcohol and to restrict advertising that falsely presents optimistic consequences of consumption.

Accurate information on negative aspects of consumption includes information on self-control issues and on genetic information that might suggest future dependency problems. Goldstein (2001: 113) argues that '...children of alcoholics should be advised to never touch alcohol; certainly they should be taught the special hazards that alcohol holds for them - hazards not shared by their peers'.

A difficulty stems from disagreement over precise health consequences of consuming alcohol among those without genetic predispositions to alcoholism. The debate over possible health benefits from reducing heart disease is an instance. Health benefits claimed to arise from consuming alcohol appear to be a spurious consequence of including among non-drinkers those who have ceased drinking because of poor health (Fillmore 2006). Apart from providing known information there is a case for investing in improved information.

As mentioned, the case for health-risk warnings is weakened if people already exaggerate risks. If particular at-risk groups or particular health concerns arise, these should be targeted rather than providing general health warnings to groups who, on average, assess risks adequately. Information targeting youth should address risks of consumption, while information targeting problem drinkers needs to address risks, problem-recognition, denial and dependency treatment.

2. Self-control policies: Problem drinkers are a sizeable sub-population whose excessive drinking is hazardous to health.

For many heavy drinkers, alcohol is not an ordinary consumer good whose consumption can be analysed using static, rational choice models. People become addicted to alcohol in an unconscious process that eventually takes over their lives. Unless consumers set out initially to become dependent, such heavy drinkers are not 'rational addicts' (Becker and Murphy 1988). Heavy drinkers typically start drinking as adolescents when excessive consumption is linked to incomplete development of brain regions involved with executive control and motivation. The vulnerability to alcoholism is greatest among individuals who start consuming early in life but those with difficulties making rational choices 
at any age tend to be alcohol abusers. Abusers have a higher incidence of mental disorders (depression, anxiety, ADHD and schizophrenia) than the general population and apparently use alcohol and other drugs to self-medicate (Koob and Moal 2006).

Genetic influences on propensities to consume alcohol may underlie personality traits such as impulsivity, risk-taking and stress responsivity that drive excessive consumption. Family and twin epidemiological studies suggest heritability of vulnerability to addictive diseases of 30-60 per cent (Kreek et al. 2005).

Like other addictive drugs (opioids, stimulants, nicotine, marijuana) and natural rewards (food, sex, water) alcohol produces euphoria by activating pleasure centres in the brain. Like other drugs, alcohol releases dopamine in the brain where pleasure centres that have evolved to ensure survival get 'hijacked'. The euphoria induced by alcohol, particularly if enhanced by a genetic predisposition, encourages repeated use. Over time, alcohol disrupts brain reward circuits and can produce withdrawal and craving if consumption ceases. Such negative reinforcements alternate with positive reinforcement to drive a cycle of addiction that becomes etched into brain structures. This etching reinforces pursuit of alcohol consumption, as a surrogate for survival-related behaviour, by dominating attention and decision-making.

Problem drinkers come to drink too much and face difficulties limiting consumption during particular episodes, with the first drink leading to uncontrolled drinking. Moreover, these compulsions can be long-term. Environmental cues associated with alcohol (people, places, advertisements) can trigger intense cravings among those addicted which cause relapse into use even after protracted abstinence.

Consumers in this cue-driven environment make consumption decisions with limited rationality and foresight. Policies for improving self-control include helping to demonstrate that alcoholism can be a consequence of recurrent drinking and desensitising and limiting exposure to cues. There can also be attempts to improve self-control by promoting 'personal rules' or heuristics to control behaviour. Since problems with alcohol consumption primarily stem from excessive consumption, 'personal rules' relating to the number of 'standard drinks' consumed per week, numbers of alcohol-free days or, in some cases, pursuit of total abstinence are useful information policies.

Self-control can also be improved by supply restrictions such as limiting the availability of alcohol outlets, trading hours and promotion of advertising that might trigger cues to drink. Unfortunately, such policies increase 'user costs' of consumption that impact on all consumers. 
Supply-control measures on alcohol outlets and on opening hours will limit external costs of alcohol consumption (Donnelly et al. 2006) and, by limiting cues, promote individual abilities to control drinking. By keeping away from cues and knowing that, beyond a certain time, drinking is impossible, people with self-control problems can be helped to formulate personal rules which limit drinking.

Restrictions on advertising help curb drinking among abstaining problem drinkers subject to cues. Indeed, as with smoking, there is a case for limiting cues in the media that elicit consumption.

For age and ethnic groups prone to excessive consumption because of self-control problems, there can be a case for consumption bans. Minimum-age laws and restrictions of alcohol availability to particular ethnicities, such as Australian aborigines, are controversial policies. Anderson and Wild (2007), however, supported such interventions resulting in the Northern Territory Emergency Response by the Howard Government in 2007. Aboriginal people are often alcohol-abstinent; but, those who do drink, often consume more than 13 standard drinks per episode (ABS 1994) and are therefore an 'at-risk' group.

With respect to drink-driving issues, the installation of ignition interlock devices can improve the judgment and self-control of drinkers in their ability to safely drive after consuming alcohol (ICADTS 2002).

Finally, treatment options emerge as a way of addressing excessive use. A substantial literature shows that local GPs can be effective in providing early interventions to caution people concerning alcohol problems (Johansson 2002). Promoting a variety of behavioural and cognitive therapies makes sense, as do traditional routes to control such as Alcoholics Anonymous. Given the social costs of alcoholism, there is a case for subsidising such services on the basis of their cost-effectiveness.

For problem drinkers, treatment options include pharmacotherapies using drugs such as naltrexone (Volpicelli et al. 1992). Naltrexone reduces recurrent daily drinking, diminishes alcohol-induced cravings and even reduces cravings after a 'priming' drink. It therefore limits the tendencies to lose control. The drug acomprosate suppresses cravings and relapse problems and can be used with naltrexone (Rösner 2008). With external costs, there is again a case for subsidising pharmacotherapies.

3. Externality policies: Economists focus on externalities as the primary source of social costs in relation to substance abuse. The standard prescription is to levy a tax internalising the external costs.

Externalities such as drink-driving-induced accidents cannot be dealt with by a consumption tax since this externality stems from the combined activities of drinking and driving. Moreover, the probability of an accident, given a certain 
level of alcohol consumption, falls with age (Phelps 1997: 516). A driver aged $20+$ who has consumed six standard drinks and then drives has 12-times the chance of a fatal crash than a similarly-aged sober driver. For a driver aged 16-19, the risk increases to 100-times that of a similarly-aged driver. Inevitably, highway patrols and booze buses must detect drink-driving, with the driver then being penalised, rather than employing taxes on consumption. It makes sense to impose stringent restrictions on alcohol consumption by young drivers.

It is only if certain alcohol-related externalities are related to overall population alcohol consumption - the 'population health' view (Young 1998) - that simple uniform tax policies make sense.

In Figure I the market demand for alcohol ( $q$ litres) is illustrated with the marginal production cost $\mathrm{c}(\mathrm{q})$. The area under the demand curve measures private benefits from drinking. Social marginal costs of consumption are also illustrated. These comprise the private marginal costs borne by consumers and the external social costs generated, including health and traffic accident costs borne by the community as well as dollar costs of violence and anti-social behaviour to others. As drawn, there are no external benefits associated with alcohol consumption at low consumption levels and external marginal costs are low. As market consumption increases, external costs rise at an increasing rate. Without taxes, consumers operate where private marginal benefits equal private marginal costs - they consume $\mathrm{q}_{2}$ and pay price $\mathrm{p}_{2}$. Because social costs exceed marginal benefits over the range $q_{1}$ to $q_{2}$, this consumption imposes net social costs or deadweight losses (DWLs) equal to area $\mathrm{ABC}^{4}$

The standard economic prescription to remove these costs is to levy a Pigovian tax $t$ which, assuming competition, raises the alcohol price to $p_{1}$, leaving consumption where marginal private benefits equal marginal social costs at $\mathrm{q}_{1}$.

Determining this tax requires assessing the scale of the unpaid-for social costs, how these are linked to consumption and the elasticity of demand for alcohol. The more responsive demand is, the smaller the tax can be. Selvanathan et al. (2004) provide elasticity estimates of $-0.3,-0.4$ and -1.3 for Australian beer, wine and spirit consumption, respectively. For alcoholic beverages as a whole, the estimated elasticity is -0.6 , suggesting that a 10 per cent tax induces 6 per cent less consumption. ${ }^{5}$

If social costs are related to the alcohol content of drinks, this tax should reflect this by being a volumetric tax related to the alcohol content of particular

${ }^{4}$ Firms will produce where price equals marginal cost if they are competitive. With monopoly power, price exceeds costs, creating deadweight losses but reducing external costs perhaps significantly (Nelson 2003).

${ }^{5}$ A distinction is drawn between short- and long-run elasticities. The latter account for effects of current consumption on future behaviour. One issue is whether forward-looking behaviour is rational. Baltagi (2007) surveys recent literature. 
types of alcoholic beverages, not an ad valorem excise levied on the value of the product sold. Alcohol products in Australia are taxed approximately volumetrically, although spirits are subject to twice the charge on alcohol content than beer, and wine is subject to ad valorem duty (Commonwealth of Australia 2005: chapter 5). In 2004-05, \$5.1 billion was collected as excise and customs duty (AIHW 2007). For years where comparable data is available, these revenues greatly exceed gross health and even costs attributable to traffic accidents (Collins \& Lapsley 2002: 62-65).

\section{Figure 1: External costs of alcohol consumption}

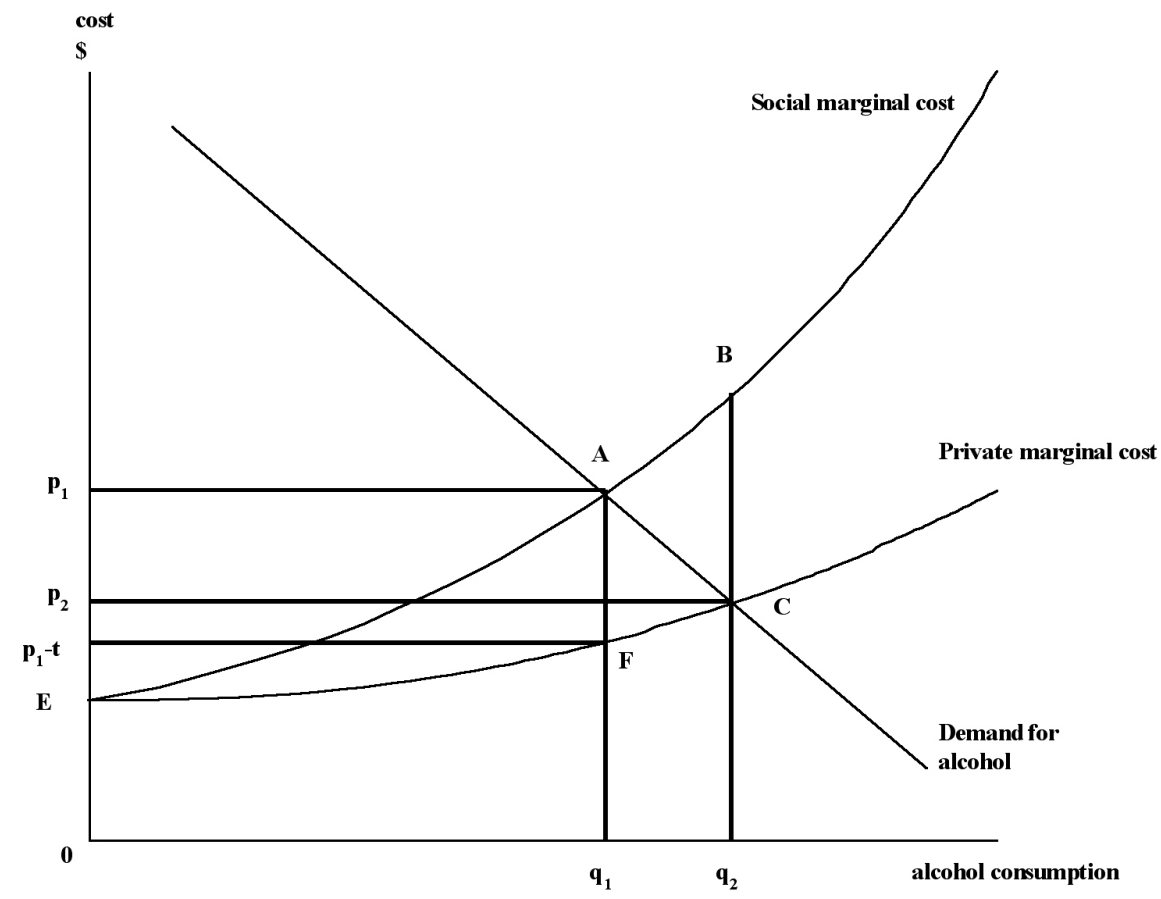

This economic approach to taxation does not focus on the gross costs of consumption, GC - the total medical and other costs attributable to alcohol. In the figure, these are the area $0 \mathrm{q}_{2} \mathrm{BE}$. Nor does it focus on non-internalised net costs less benefits (NC) of alcohol - the medical and other costs not borne by alcohol consumers less consumption benefits, given by area ECB. Instead, the economic approach recognises that alcohol consumption yields benefits to consumers, given by the area under the demand curve. Thus a tax-inclusive price is sought that maximises the net social advantage - benefits derived less all costs, whether internalised or not.

Indeed DWLs $<<$ NC $<<$ GC where $<<$ means 'is much less than'. Thus setting tax t eliminates society's deadweight losses and reduces, but does not eliminate, net and gross costs of consumption. 
Note that optimal tax revenues, $\mathrm{tq}_{1}$, exceed non-internalised social costs EAF because social marginal costs increase strongly as consumption levels increase. Therefore, evidence showing that alcohol consumers pay more taxes than are imposed in external costs does not support the conclusion that taxes are 'too high' as claimed by, for example, Heien (1995) using 'reparationist logic'. It is only if non-internalised, marginal external costs were constant, so private and social marginal cost curves are parallel, that tax revenues should coincide with unpaid external costs to achieve social optimality. But social damages are, most plausibly, strongly increasing in alcohol consumption. Thus taxes ideally should exceed damages, rather than merely compensating society for damages done.

Empirically the social costs of alcohol consumption must be computed net of external benefits. People who die from alcohol consumption create a social benefit in terms of reduced costs of aged care and reduced costs of treating other diseases that would have impacted on mortality if alcohol consumption was curtailed. If there are external benefits from alcohol's ability to catalyse social interactions which help create social capital, these too should be netted out.

There are several reservations concerning this standard tax prescription.

(i) The approach optimises the overall social advantage but has distinct effects on different community groups. Taxes levied are inevitably uniform - they do not vary by consumer. If a minority of alcohol consumers has very inelastic demands because of self-control issues then their consumption would need to be constrained by high taxes if it is to be curtailed. Such taxes would impose heavy DWLs on those consuming at moderate levels, who impose low social costs. Some 74 per cent of Australians aged 14 years and above consumed alcohol in quantities considered 'low risk' to health but paid hefty alcohol taxes (AIHW 2005). Setting lower taxes, however, to cater for those imposing low social costs, leaves the behaviour of those with inelastic demands who impose large social costs largely unchanged while significantly reducing their real incomes. If heavy consumers have low incomes, this raises equity issues. While gainers from efficient taxes can, in principle, compensate losers, this compensation is difficult to engineer in practice.

Such distributional issues constrain policy. Indeed, some argue that 'a tax on alcohol would reduce consumption indiscriminately... and therefore reduce the satisfaction experienced by millions of sensible drinkers without necessarily reducing the harm caused by a few excessive drinkers' (Littlefield 1986: 274).

High taxes may encourage the decision to quit entirely but, given an alcoholic's compulsion to not stop at one drink, will not markedly reduce the intensity of drinking during particular consumption episodes. In their favour, high taxes have major effects in restricting alcohol consumption among adolescents (Saffer and Dave 2003). 
The question of whether low levels of drinking are harmful - or even beneficial - is controversial. In assessing workforce costs, Pidd et al. (2006) used self-reported measures of alcohol-related absenteeism to estimate 2.7 million workdays were lost due to alcohol use in 2001, costing \$437 million. Self-reported measures of illness or injury absenteeism to determine absenteeism attributable to alcohol use resulted in an estimate of 7.4 million workdays lost, costing \$1.2 billion. Low-risk drinkers and infrequent or occasional risky and high-risk drinkers accounted for 49-66 per cent of this absenteeism. This estimated cost of alcohol-related absenteeism is far greater than previously reported and the high incidence of costs by low-risk drinkers and those who infrequently drink heavily was unexpected.

One approach to addressing concerns that external costs are concentrated among a narrow group of high-consumption users is to levy moderate taxes but to penalise intensively socially costly actions associated with high alcohol consumption. Drink-driving and alcohol-related assault should be intensively penalised as activities in themselves. Thus, the intoxicated person who walks home from the pub and 'sleeps it off' is not taxed prohibitively; but if the same person drives home or assaults a family member, then stringent penalties obtain. Alcohol taxes in this event capture non-extreme social costs while particular laws seek to capture externality costs.

(ii) Using volumetric taxes to penalise low-value, high-alcohol products creates incentives for unfavourable substitutions towards other intoxicants. A widespread intoxicant in Aboriginal communities is sniffed petrol, so there are incentives to shift towards this if low-cost high-alcohol beverages become more expensive. This is a 'second-best' constraint on alcohol taxes that reflects the existence of untaxed substitute intoxicants.

Whether alcohol taxes will induce substitution towards alternative drugs depends on whether alcohol and the drugs are substitutes - Cameron et al. (2001) suggest cannabis and alcohol are substitutes - or complements. Williams et al. (2004) suggest alcohol and cannabis are complements, so increasing the price of alcohol will reduce cannabis consumption.

Attempts to tax alcohol-induced social costs efficiently require that close-substitute intoxicants also be taxed or regulated efficiently. Policy design must account for such cross-market interactions.

(iii) Measures of consumer gain from alcohol consumption given by the area under a demand curve are exaggerated if there are self-control problems. These can be dealt with by adjusting downward benefit measures to account for compulsive consumption: the technique is used for gambling addictions (Productivity Commission 1999). 
Finally, apart from implementation difficulties some have argued that there is a case for hypothecating a proportion of alcohol taxes to targeted alcohol treatment and information programs (RACP 2005). The motivation is that such revenues reflect social costs that alcohol creates. This is not true with the social costs we have envisaged, which increase more than proportionately with total consumption so optimal tax revenues exceed non-internalised costs. Hypothecation is unsound anyway since desired investment depends on program effectiveness, not only the damages alcohol inflicts. To take an extreme case, if such programs had low effectiveness then little should be allocated even if social costs are large. The function of taxes on alcohol is primarily to signal the social costs consumers are imposing at the margin. Their revenue-yielding function is secondary.

\section{Final comments}

The economic approach to alcohol policy focuses on the external costs of consuming alcohol, not gross costs. It recognises that alcohol provides benefits to consumers and supposes that internalised costs of use borne by non-dependent consumers are irrelevant from society's viewpoint. This is based on the utilitarian precept that consumers should bear the full costs of their consumption and that, given this, society should maximise net social benefits.

This approach provides a guide to policy design with secure utilitarian foundations. Information should be provided to consumers so they assess consumption costs accurately, including genetic information and self-control problems that can develop. Self-control difficulties can be addressed with appropriate policies for treatment and by adjusting measures of benefits from consumption. With such adjustments, alcohol pricing forces prices of alcohol to full social cost (Godfrey 2004)).

Despite these reasons for adopting the economic approach it has, in fact, been applied only rather seldom. The main studies are for the US - Manning et al. (1989), Pogue \& Sgontz (1989), Heien \& Pittman (1993) — and New Zealand (Barker (2002). Anderson and Braumberg (2006: 68-9), in reviewing these, comment on the difficulties of implementing them given problems of defining externalities and of recognising the private component of health costs with a public health system:

...externality studies...omit any consideration of the broad range of costs borne by the individual drinker, and are more useful when conducted alongside rather than in place of more common social cost studies. This is particularly true given two contentious results of the assumptions in many externality studies - first, that any harm within the household (such as to the drinker's partner, or children) is counted as a private cost; 
and second, that drinkers are both fully rational and fully informed of the risks when they decide to drink.

This criticism rejects the liberal ethic underlying the economic approach. The claim that intra-family harm should be included as a private cost was rejected above because families do not make drinking decisions; individuals do. The argument that groups of non-drinkers can best judge what a consumer should consume is not always correct. Policies can be designed which address the needs of problem drinkers while meeting liberal precepts and standards of economic efficiency for most drinkers. To a liberal, paternalism is a questionable overall basis for public policy.

Finally, it can be questioned whether this analysis applies to illicit substances such as heroin or 'ice'. A distinctive feature of these substances is that their consumption is socially costly even at low initial levels, suggesting a case for outright prohibition rather than regulation by taxes. With respect to activities such as gambling and food consumption, which can be behaviourally addictive and, in the case of foods, can lead to obesity problems, our analysis has value. Taxes on gambling (Productivity Commission 1999) and 'fat taxes' on foods (Jacobson and Brownell 2000) restrict consumption and can be pursued with policies to address self-control issues.

\section{References}

Anderson, P. and Braumberg, B. 2006, Alcohol in Europe: A Public Health Perspective, Institute of Alcohol Studies for the European Commission, at: http://ec.europa.eu/health-eu/news_alcoholineurope_en.htm.

Anderson P. and Wild, R. 2007, Little children are sacred: report of the Northern Territory Board of Inquiry into the protection of Aboriginal children from sexual abuse 2007, Darwin: Northern Territory Government.

Australian Bureau of Statistics (ABS) 2006, Alcohol Consumption in Australia: A Snapshot, 2004-05, Canberra, 4832.0.55.001.

Australian Bureau of Statistics (ABS) 1994, Urban Aboriginal and Torres Strait Islander Supplement, National Drug Strategy Household Survey, Canberra.

Australian Institute of Health and Welfare (AIHW) 2004, National Drug Strategy Household Survey, Department of Health and Aging, Canberra: 2005.

Australian Institute of Health and Welfare (AIHW) 2006, Alcohol and Other Drug Treatment Services in Australia 2004-05, Canberra.

Australian Institute of Health and Welfare (AIHW) 2007, Statistics on Drug Use in Australia 2006, Canberra.

Baltagi, B. H. 2007, 'On the Use of Panel Data Methods to Estimate Rational Addiction Models', Scottish Journal of Political Economy 54(1): 1-18. 
Barker, F. 2002, 'Consumption Externalities and the Role of Government: The Case of Alcohol', Working Paper 02/25, 2002, New Zealand Treasury.

Becker, G. S. and Murphy, K.M. 1988, 'A Theory of Rational Addiction', Journal of Political Economy 96(4): 675-700.

Cameron, L. and Williams, J. 2001, 'Cannabis, Alcohol and Cigarettes: Substitutes or Complements?' Economic Record 77(236): 19-34.

Collins, D. J. and Lapsley, H. M. 2002, Counting the Costs: Estimates of the Social Costs of Drug Abuse, Commonwealth Department of Health and Aging, Canberra.

Commonwealth of Australia 2005, Review of the Schedule to the Excise Tariff Act, Industry Discussion Paper, Canberra.

Donnelly, N., Poynton, S., Weatherburn, D., Bamford, E. and Nottage, J. 2006, 'Liquor Outlet Concentrations and Alcohol-Related Neighbourhood Problems', Alcohol Studies Bulletin, NSW Bureau of Crime Statistics and Research, 8, 15 pages.

Fillmore, K., Stockwell, T. R., Kerr, W., Chikritzhs, T. and Bostrom, A. 2006, 'Moderate alcohol use and reduced mortality risk: systematic error in prospective studies', Addiction Research \& Theory 14(2): 101-32.

Godfrey, C. 2004, 'The Financial Costs and Benefits of Alcohol', Paper presented to the 'European Alcohol Policy Conference: Bridging the Gap', Warsaw 16-19 June, at: http://www.eurocare.org/btg/conf0604/papers/godfrey.pdf).

Goldstein, A. 2001, Addiction: From Biology to Drug Policy, Oxford University Press, Oxford, $2^{\text {nd }}$ edition.

Heien, D. M. 1995, 'Are Higher Alcohol Taxes Justified?', The Cato Journal 15(2-3): 2-7.

Heien, D. M. and Pittman, D. J. 1993, 'The External Costs of Alcohol Abuse', Journal of Studies on Alcohol 54: 302-7.

International Council on Alcohol, Drugs and Traffic Safety (ICADTS), 'Alcohol Ignition Interlock Devices', 2002, Position Paper, Norway.

Jacobson, M. F. and Brownell, K. D. 2000, 'Small taxes on soft drinks and snack foods to promote health', American Journal of Public Health 90(6): 854-7.

Johansson, K., Bendtsen P. and Åkerlind, I. 2002, 'Early Intervention for Problem Drinkers', Alcohol and Alcoholism 37(1): 38-42.

Koob G. F. and Le Moal, M. 2006, Neurobiology of Addiction, Academic Press, Oxford. 
Kreek, M. J., Nielson, D. A., Butelman, E. R. and LaForge, K. S. 2005, 'Genetic Influences on Impulsivity, Risk Taking, Stress Responsivity and Vulnerability to Drug Abuse and Addiction', Nature Neuroscience 8(11): 1450-7.

Lundborg, P. and Lindgren, B. 2002, 'Risk Perceptions and Alcohol Consumption Among Young Adolescents', Journal of Risk and Uncertainty 25: 165-83.

Littlefield, S. C. 1986, 'Smoking and Market Failure' in Tollison, R. D. (ed.), Smoking and Society: Toward a More Balanced Assessment, Lexington KY, Lexington: 271-84.

Manning, W. G., Keeler, E. B., Newhouse, J. P., Sloss E. M. and Wasserman, J. 1989, 'The Taxes of Sin: Do Smokers and Drinkers Pay Their Way?', Journal of the American Medical Association 261: 1604-9.

Nelson, J. P. 2003, 'Advertising Bans, Monopoly, and Alcohol Demand: Testing for Substitution Effects Using State Panel Data', Review of Industrial Organization 22: 1-25.

Phelps, C. E. 1997, Health Economics, Addison-Wesley.

Pidd, K. J., Berry, J. G., Roche, A. M. and Harrison, J. E. 2006, 'Estimating the cost of alcohol-related absenteeism in the Australian workforce: the importance of consumption patterns', The Medical Journal of Australia.

Pogue, T. F. and Sgontz, L. G. 1989, 'Taxing to Control Social Costs: The Case of Alcohol', American Economic Review 79(1): 235-43.

Productivity Commission 1999, Australia's Gambling Industries 1, Melbourne.

Rösner, S. 2008, 'Acomprosate supports abstinence, Naltrexone prevents excessive drinking' Journal of Psychopharmopharmacy 22(1): 11-23.

Royal Australasian College of Surgeons 2005, Alcohol Policy: Using Evidence for Better Outcomes, RACP, Sydney.

Saffer, H. and Dave, D. 2003, 'Alcohol Advertising and Alcohol Consumption by Adolescents', NBER Working Paper No. 9482, National Bureau of Economic Research.

Selvanathan, E. A. and Selvanathan, S. 2004, 'Economic and demographic factors in Australian alcohol demand', Applied Economics 36: 2405-17.

Young, T. Kue 1998, Population Health, New York, Oxford.

Viscusi, W. Kip 2002, Smoke-Filled Rooms, University of Chicago Press, Chicago.

Volpicelli, J. R., Alterman, A. I., Hayashida, M. and O'Brien, C. P., 'Naltrexone in the treatment of alcohol dependence', Archives of General Psychiatry 49: 876-80. 
Agenda, Volume 15, Number 2, 2008

Williams, J., Pacula, R., Chaloupa, F. J. and Wechsler, H. 2004, 'Alcohol and Marijuana Use Among College Students: Economic Complements or Substitutes?', Health Economics 13(9): 825-43

World Health Organisation 2004, Global Status Report on Alcohol 2004, World Health Organisation, Geneva. 